BMC

Microbiology

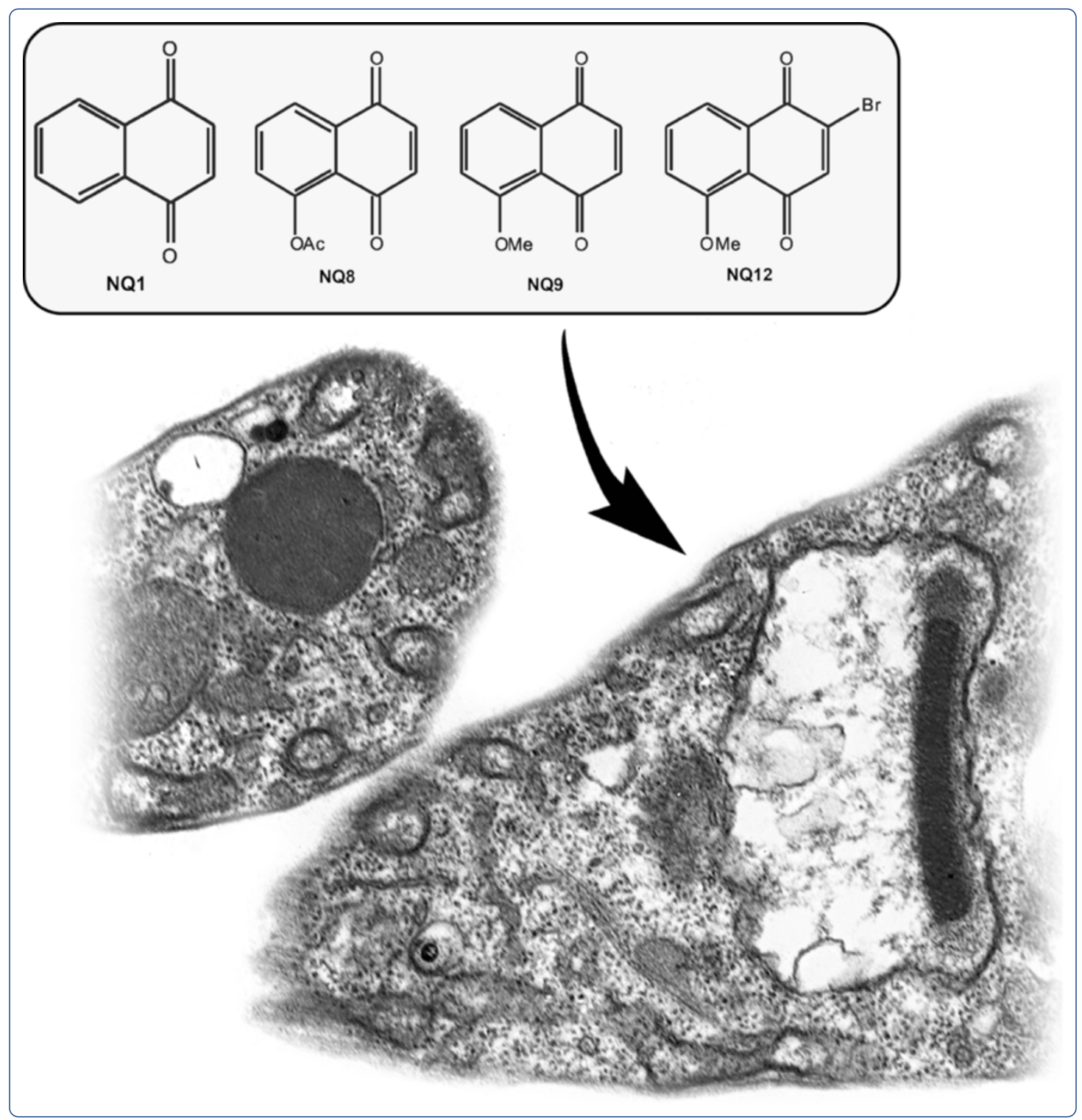

\title{
Trypanosoma cruzi mitochondrial swelling and membrane potential collapse as primary evidence of the mode of action of naphthoquinone analogues
}

Salomão et al.

C Biomed Central 


\title{
Trypanosoma cruzi mitochondrial swelling and membrane potential collapse as primary evidence of the mode of action of naphthoquinone analogues
}

Kelly Salomão ${ }^{1}$, Natalia A De Santana ${ }^{1}$, Maria Teresa Molina ${ }^{2}$, Solange L De Castro ${ }^{1 *}$ and Rubem F S Menna-Barreto ${ }^{1}$

\begin{abstract}
Background: Naphthoquinones (NQs) are privileged structures in medicinal chemistry due to the biological effects associated with the induction of oxidative stress. The present study evaluated the activities of sixteen NQs derivatives on Trypanosoma cruzi.

Results: Fourteen NQs displayed higher activity against bloodstream trypomastigotes of T. cruzi than benznidazole. Further assays with NQ1, NQ8, NQ9 and NQ12 showed inhibition of the proliferation of axenic epimastigotes and intracelulluar amastigotes interiorized in macrophages and in heart muscle cells. NQ8 was the most active NQ against both proliferative forms of T. cruzi. In epimastigotes the four NQs induced mitochondrial swelling, vacuolization, and flagellar blebbing. The treatment with NQs also induced the appearance of large endoplasmic reticulum profiles surrounding different cellular structures and of myelin-like membranous contours, morphological characteristics of an autophagic process. At IC $\mathrm{C}_{50}$ concentration, NQ8 totally disrupted the $\Delta \psi \mathrm{m}$ of about $20 \%$ of the parasites, suggesting the induction of a sub-population with metabolically inactive mitochondria. On the other hand, NQ1, NQ9 or NQ12 led only to a discrete decrease of TMRE + labeling at IC 50 values. NQ8 led also to an increase in the percentage of parasites labeled with DHE, indicative of ROS production, possibly the cause of the observed mitochondrial swelling. The other three NQs behaved similarly to untreated controls.

Conclusions: NQ1, NQ8, NQ9 and NQ12 induce an autophagic phenotype in T. cruzi epimastigoted, as already observed with others NQs. The absence of oxidative stress in NQ1-, NQ9- and NQ12-treated parasites could be due to the existence of more than one mechanism of action involved in their trypanocidal activity, leaving ROS generation suppressed by the detoxification system of the parasite. The strong redox effect of NQ8 could be associated to the presence of the acetyl group in its structure facilitating quinone reduction, as previously demonstrated by electrochemical analysis. Further experiments using biochemical and molecular approaches are needed to better characterize ROS participation in the mechanism of action of these NQs.
\end{abstract}

Keywords: Rypanosoma cruzi, Naphthoquinones, Juglone, Experimental chemotherapy, Mitochondria

\footnotetext{
*Correspondence: solange@ioc.fiocruz.br

${ }^{1}$ Laboratório de Biologia Celular, Instituto Oswaldo Cruz, Fundação Oswaldo

Cruz, Av. Brasil 4365, Manguinhos, Rio de Janeiro RJ 21040-900, Brazil

Full list of author information is available at the end of the article
} 


\section{Background}

Chagas' disease (CD), caused by Trypanosoma cruzi, affects approximately eight million individuals in Latin America $[1,2]$ and is emerging in non-endemic areas due to the globalization of immigration and non-vector transmission routes [3]. The available therapy for $\mathrm{CD}$ is based on two nitroheterocycles, benznidazole $(\mathrm{Bz})$ and nifurtimox, and was developed more than four decades ago. Both nitroheterocycles are far from ideal due to substantial secondary side effects, limited efficacy against different parasite isolates, the need for long-term therapy and their well-known poor activity in the late chronic phase. These drawbacks justify the urgent need to identify better drugs to treat chagasic patients [4].

Naphthoquinones account for the largest number of natural naphthalenes, holding a number of different substituents with a variety of structural motifs. They act as vital links in the electron transport chains in metabolic pathways and participate in multiple biological oxidative processes [5]. Quinone-containing plants have been used in diverse cultures as dyes, cosmetics, and food and, especially among Indian populations, for the treatment of different diseases [6,7]. Naphthoquinones are considered privileged structures in medicinal chemistry due to their structural properties and biological activities [8], especially against tumor cells and pathogenic protozoa $[9,10]$. Two major mechanisms of quinone cytotoxicity have been proposed: stimulation of oxidative stress and alkylation of cellular nucleophiles, which are the mechanisms of action common to a large range of biomolecules [11].

Among the simple hydroxylated naphthoquinones, juglone (5-hydroxy-1,4-naphthoquinone), isolated from walnut trees (Juglandaceae), has shown a variety of biological effects, including microbicidal [12], antiinflammatory [13] and antitumoral [14,15] effects that are associated with the induction of oxidative stress. As part of our continuing program of screening natural and synthetic quinones for trypanocidal activity, in the present work we investigated the activity and mode of action of naphthoquinones and specific juglone derivatives.

\section{Results}

\section{Activity on bloodstream trypomastigotes}

In the present work, we initially evaluated the efficacy of sixteen 1,4-naphthoquinones (1,4-NQs) against the infective bloodstream trypomastigote forms of $T$. cruzi at $37^{\circ} \mathrm{C}$ in Dulbecco's modified Eagle's medium (Sigma-Aldrich) plus $10 \%$ fetal calf serum (DMES) (Table 1). The prototype, 1,4-naphthoquinone (NQ1), was compared with other derivatives that were substituted at $\mathrm{C}-2$ with methyl (NQ2), hydroxyl (NQ3), acetoxy (NQ4), and bromo (NQ5) groups or that were disubstituted at $\mathrm{C}-2$ and $\mathrm{C}-3$, such as 2,3dichoro-1,4-naphthoquinone (NQ6). In addition, juglone (NQ7) and its derivatives, including those brominated at
Table 1 Activity of the naphthoquinones on bloodstream trypomastigotes of $T$. cruzi at $37^{\circ} \mathrm{C}$

\begin{tabular}{lll}
\hline Cpd & Nomenclature $^{\mathbf{a}}$ & $\mathbf{I C}_{\mathbf{5 0}} \mathbf{/ 2 4} \mathbf{h}(\boldsymbol{\mu M})$ \\
\hline NQ1 & 1,4-Naphthoquinone & $0.79 \pm 0.02$ \\
NQ2 & 2-Methyl-1,4-naphthoquinone (menadione) & $6.04 \pm 0.35$ \\
NQ3 & 2-Hydroxy-1,4-naphthoquinone (lawsone) & $563.18 \pm 83.28$ \\
NQ4 & 2-Acetoxy-1,4-naphthoquinone & $63.02 \pm 5.8$ \\
NQ5 & 2-Bromo-1,4- naphthoquinone & $1.37 \pm 0.03$ \\
NQ6 & 2,3-Dichloro-1,4- naphthoquinone (dichlone) & $2.17 \pm 0.29$ \\
NQ7 & 5-Hydroxy-1,4-naphthoquinone (juglone) & $6.51 \pm 0.48$ \\
NQ8 & 5-Acetoxy-1,4- naphthoquinone & $0.16 \pm 0.01$ \\
NQ9 & 5-Methoxy-1,4-naphthoquinone & $1.02 \pm 0.29$ \\
NQ10 & 2-Bromo-5-hydroxy-1,4-naphthoquinone & $2.15 \pm 0.22$ \\
NQ11 & 2-Bromo-5-acetoxy-1,4-naphthoquinone & $2.43 \pm 0.50$ \\
NQ12 & 2-Bromo-5-methoxy-1,4-naphthoquinone & $1.25 \pm 0.26$ \\
NQ13 & 3-Bromo-5-hydroxy-1,4-naphthoquinone & $2.52 \pm 0.37$ \\
NQ14 & 3-Bromo-5-acetoxy-1,4-naphthoquinone & $0.85 \pm 0.08$ \\
NQ15 & 3-Bromo-5-methoxy-1,4-naphthoquinone & $1.41 \pm 0.15$ \\
NQ16 & 2-Methyl-5-hydroxy-1,4-naphthoquinone & $1.38 \pm 0.26$ \\
& (plumbagin) & \\
Bz & Benznidazole & $26.0 \pm 4.0$ \\
\hline The bromo derivatives (NQ10-NQ15) are named based on the core juglone \\
(NQ7) system.
\end{tabular}

C-2 (NQ10 to NQ12) or C-3 (NQ13 to NQ15) and 2methyl-5-hydroxy-1,4-naphthoquinone (NQ16), were also examined. Fourteen compounds displayed an $\mathrm{IC}_{50}$ in the range of 0.16 to $6.51 \mu \mathrm{M}$, demonstrating higher activity than $\mathrm{Bz}(26.0 \mu \mathrm{M})$, and the other two tested compounds were less active: NQ3 $(563.18 \mu \mathrm{M})$ and NQ4 $(63.02 \mu \mathrm{M})$ (Table 1).

Among the most active compounds on trypomastigotes at $37^{\circ} \mathrm{C}$, four were selected for further studies: the prototype naphthoquinone (NQ1) and three juglone derivatives (NQ8, NQ9 and NQ12) (Figure 1). Interestingly, their activity against trypomastigotes was not decreased when the experiments were performed at $4^{\circ} \mathrm{C}$ in culture medium, but at this lower temperature in the presence of whole blood, $\mathrm{IC}_{50}$ values higher than $500 \mu \mathrm{M}$ were obtained (data not shown).

\section{Activity on the proliferative forms of $T$. cruzi and toxicity to mammalian cells}

The selected compounds (NQ1, NQ8, NQ9 and NQ12) were also assayed using the proliferative forms of $T$. cruzi: axenic epimastigotes and intracellular amastigotes. A dose-dependent effect on epimastigotes was observed, leading to the $\mathrm{IC}_{50}$ values for proliferation inhibition for 1 to 4 days of treatment displayed in Table 2. Comparing the four NQs, the prototype unsubstituted quinone NQ1 was the most active against epimastigotes. 
The NQs were added to T. cruzi-infected primary cultures of both peritoneal macrophages and HMCs after the removal of non-interiorized parasites. For both host cells the inhibitory effect on the percent infection was in the range of 0.5 to $5.0 \mu \mathrm{M}$. Surprisingly, NQ8 and NQ9 caused about a 2.5-fold decrease of infection. For both host cells, the $\mathrm{IC}_{50}$ values after $48 \mathrm{~h}$ of treatment used to calculate the endocytic index are displayed in Table 3. NQ8 was the most active compound. Non-infected macrophages and HMCs treated with the compounds for 2 days were tested with the MTT assay to evaluate their toxicity to mammalian cells. For HMCs, the $\mathrm{LC}_{50}$ values were $8 \mu \mathrm{M}$ for NQ1 and NQ12 and $10 \mu \mathrm{M}$ for NQ8; NQ9 was the least toxic quinone with values higher than $10 \mu \mathrm{M}$. The $\mathrm{LC}_{50}$ was higher than $10 \mu \mathrm{M}$ in macrophages for all four compounds.

\section{Ultrastructural analysis}

Transmission electron microscopy showed that treatment with the NQs induced important alterations in the mitochondrion of the epimastigotes, leading to swelling and the appearance of membranous structures in the organelle matrix (Figures 2, 3, 4 and 5). Autophagic features, such as atypical cytosolic membranous structures
Table $2 \mathrm{IC}_{50}$ values $(\mu \mathrm{M})$ of the naphthoquinones on the proliferation of $T$. cruzi epimastigotes

\begin{tabular}{lllll}
\hline Cpd & $\mathbf{1}$ day & $\mathbf{2}$ days & $\mathbf{3}$ days & 4 days \\
\hline NQ1 & $0.30 \pm 0.08^{\mathrm{a}}$ & $0.24 \pm 0.03$ & $0.26 \pm 0.04$ & $0.26 \pm 0.05$ \\
NQ8 & $0.76 \pm 0.12$ & $0.35 \pm 0.09$ & $0.24 \pm 0.10$ & $0.36 \pm 0.07$ \\
NQ9 & $2.62 \pm 0.38$ & $1.05 \pm 0.19$ & $1.08 \pm 0.17$ & $1.27 \pm 0.21$ \\
NQ12 & $0.55 \pm 0.01$ & $0.48 \pm 0.06$ & $0.45 \pm 0.05$ & $0.44 \pm 0.11$ \\
\hline
\end{tabular}

${ }^{\mathrm{a}}$ Mean \pm standard deviation of at least three independent experiments.

(Figures 3, 4, 5) and the appearance of endoplasmic reticulum surrounding reservosomes (Figures 2 and 5), were detected in treated parasites. The naphthoquinones also led to intense cytosolic vacuolization (Figures 4 and 5), the formation of blebs in the flagellar region (Figures 2, 3 and 5) and the induction of loss of the electron-density of the cytosol (washed out aspect) (Figures 3 and 5). The scanning electron microscopy technique demonstrated no important morphological alterations in treated epimastigotes (data not shown).

\section{Flow cytometry analysis}

This technique was employed to evaluate the mitochondrial membrane potential $(\Delta \Psi \mathrm{m})$ dissipation by labeling<smiles>O=C1C=CC(=O)c2ccccc21</smiles><smiles>O=C1C=C(Br)C(=O)c2ccccc21</smiles><smiles>COc1cccc2c1C(=O)C=CC2=O</smiles>

NQ9<smiles>O=C1C=C(Br)C(=O)c2c(O)cccc21</smiles><smiles>CC1=CC(=O)c2ccccc2C1=O</smiles>

NQ2<smiles>O=C1C(Cl)=C(Cl)C(=O)c2ccccc21</smiles>

NQ6<smiles>O=C1C=C(Br)C(=O)c2c(O)cccc21</smiles><smiles>CCCCCCC(=O)Oc1cccc2c1C(=O)C(CC)=CC2=O</smiles><smiles>O=C1C=C(O)C(=O)c2ccccc21</smiles>

NQ3<smiles>O=C1C=CC(=O)c2c(O)cccc21</smiles><smiles>COc1cccc2c1C(=O)C(Br)=CC2=O</smiles><smiles>COc1cccc2c1C(=O)C(Br)=CC2=O</smiles><smiles>COC(=O)C1=CC(=O)c2ccccc2C1=O</smiles>

NQ4<smiles>COc1cccc2c1C(=O)C=CC2=O</smiles><smiles>COc1cccc2c1C(=O)C=C(Br)C2=O</smiles><smiles>CC(C)(C)O[Na]</smiles>

Figure 1 Chemical structures of the studied naphthoquinones. 


\begin{tabular}{|c|c|c|}
\hline Cpd & HMC & Macrophages \\
\hline NQ1 & $2.81 \pm 0.43^{\mathrm{a}, \mathrm{b}}$ & $3.65 \pm 0.71$ \\
\hline NQ8 & $1.53 \pm 0.11$ & $1.49 \pm 0.01$ \\
\hline NQ9 & $2.48 \pm 0.39$ & $1.63 \pm 0.18$ \\
\hline NQ12 & $9.83 \pm 2.64$ & $2.51 \pm 0.71$ \\
\hline
\end{tabular}

${ }^{\mathrm{a}}$ The $\mathrm{IC} \mathrm{C}_{50}$ was calculated for the endocytic index (number of parasites/100 host cells) after two days of treatment.

${ }^{b}$ Mean \pm standard deviation of at least three independent experiments.

epimastigotes with the specific marker TMRE in the presence of $10 \mu \mathrm{M}$ FCCP. The four NQs, at $\mathrm{IC}_{50}$ levels, induced a significant decrease in the TMRE fluorescence, denoted in Table 4 by the reduction of the IV values (see Methods) from -0.22 to -0.53 . NQ8 at the concentration of $8 \mu \mathrm{M}$ presented the most remarkable reduction in the fluorescence intensity of the marker and totally disrupted the $\Delta \Psi \mathrm{m}$ of about $20 \%$ of the parasites (Table 4). On the other hand, treatment with NQ1, NQ9 or NQ12 induced no alteration in the percentage of TMRE + epimastigotes, a finding that was quite similar to that observed in control parasites. ROS production was assessed by DHE labeling and incubation with $\mathrm{AA}$, a potent $\mathrm{ROS}$ inducer. Only treatment at the $\mathrm{IC}_{50}$ of NQ8 led to a discrete increase in the percentage of DHE + parasites (Table 4). The other three NQs yielded the same labeling pattern as the untreated cells at every dose tested.

\section{Discussion}

Initially, the sixteen derivatives were assayed against bloodstream forms of $T$. cruzi at $37^{\circ} \mathrm{C}$ (Table 1 ). The activity of NQ1 was surprising because this compound is the nonsubstituted 1,4-naphthoquinone. The introduction of a hydroxyl at C5 (NQ7, juglone) is detrimental to the trypanocidal activity, which is decreased $8 \times$ in comparison with the parent quinone. Among the three simple juglone derivatives, the substitution of a hydroxyl by an acetoxy or methoxy group leads to higher biological activity. The $O$-methylated (NQ9) and the $O$-acetylated (NQ8) juglone derivatives were $6.4 \times$ and $40 \times$, respectively, more active than juglone (NQ7) itself. Among the 2- and 3-bromojuglone derivatives (NQ10 to NQ15), regardless of the substituent, roughly the same efficacy was observed $\left(\mathrm{IC}_{50}\right.$ between 1.2 and $2.5 \mu \mathrm{M}$ ), with the exception of NQ14, which displayed trypanocidal activity similar to that of nonsubstituted NQ1. Moreover, NQ12 and NQ15 are very similar and, in both cases, are slightly less effective than the parent methyl ether NQ9. This trend is also valid among the 5-hydroxy derivatives. Thus, NQ10 and NQ13 had similar activity but showed 3-fold higher activity than juglone itself (NQ7).
The effect of the juglone derivatives was previously investigated on Aedes aegypti, the vector of dengue, and on adult Biomphalaria glabrata snails [16]. Concerning the larvicidal activity, NQ10, NQ11 and NQ13 were the most active, with $\mathrm{IC}_{50}$ values of about $4 \mu \mathrm{M}$. With respect to their molluscidal effects, NQ11, NQ12, NQ14 and NQ15 had ranges of activity between 1.8 and $3.2 \mu \mathrm{M}$. Cytotoxic assays using four human cancer cell lines revealed that NQ9 was the most active, with $\mathrm{IC}_{50} /$ $72 \mathrm{~h}$ values ranging from 1.7 to $4.7 \mu \mathrm{M}$, whereas for juglone (NQ7), this range was from 7.6 to over $28.7 \mu \mathrm{M}$ [14]. The mechanism underlying the cytotoxicity of NQ9 to HL-60 cells involved the activation of caspases leading to an induction of apoptosis independent of mitochondria depolarization [14].

Leaving aside the juglone derivatives, and with the exceptions of NQ3, previously shown by us as inactive against $T$. cruzi in other experimental conditions [17], and of NQ4, all the compounds displayed $\mathrm{IC}_{50}$ values in the range of 1.37 (NQ5) to 6.04 (NQ2) $\mu \mathrm{M}$, corresponding to a higher activity in comparison with the standard drug benznidazole, which has an $\mathrm{IC}_{50}$ value of $26.0 \pm$ 4.0 $\mu \mathrm{M}$. In a study with Bolivian medicinal plants, Fournet and colleagues $[18,19]$ reported the potent effect of NQ16 (plumbagin), isolated from Pera benensis, against T. cruzi and different species of Leishmania.

The four compounds that were most active on bloodstream forms at $37^{\circ} \mathrm{C}$ were assayed also at $4^{\circ} \mathrm{C}$ : in the absence of blood, the lytic effect on trypomastigotes was not decreased, while in the presence of whole blood, $\mathrm{IC}_{50}$ values higher than $500 \mu \mathrm{M}$ were obtained. These results are consistent with previous reports on the literature regarding the inactivation of the trypanocidal activity of quinones in the presence of blood components $[17,20]$. Comparing the susceptibility of the different developmental forms of $T$. cruzi to the compounds, it was observed that bloodstream trypomastigotes were more susceptible to NQ8, whereas epimastigotes were more susceptible to NQ1. Intracellular amastigotes from heart muscle cells or peritoneal macrophages were at least 2-fold more resistant to treatment with NQ1, NQ8 and NQ12.

For the subsequent investigation of the mode of action of the four selected NQs, electron microscopy and flow cytometry assays with epimastigotes were employed, never exceeding the respective IC50 values. Treatment with these compounds led to remarkable ultrastructural alterations, especially in the mitochondrion. The appearance of different morphological features suggestive of autophagic activity and the interference in flagellar membrane fluidity with bleb formation were also recurrent alterations.

Mitochondrial susceptibility to treatment with naphthoquinones and its derivatives has been extensively 


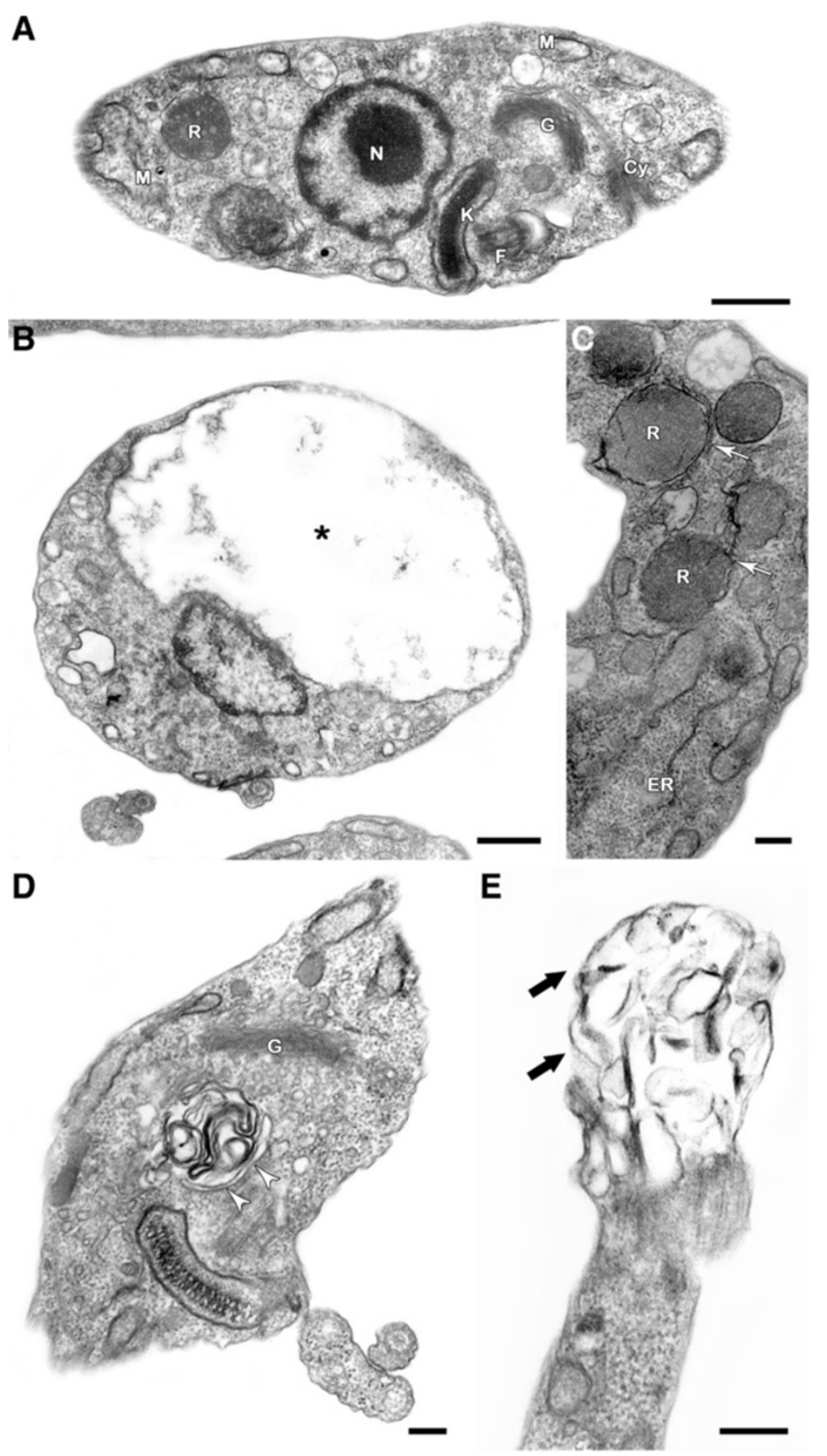

Figure 2 Transmission electron microscopy analysis of $T$. cruzi epimastigotes treated with NQ1. (A) Untreated epimastigote showing normal ultrastructural aspect and presenting typical morphologies of the mitochondrion (M), kinetoplast (K), flagellum (F), nucleus (N), Golgi (G), reservosome (R) and cytostome (Cy). (B-E) The concentration of $0.3 \mu \mathrm{M}$ NQ1 led to swelling in the mitochondrion $\left(^{*}\right)$, the formation of abnormal cytosolic membranous structures (white arrowheads) and the appearance of endoplasmic reticulum surrounding reservosomes (white arrows). Blebs (thick black arrows) was formed in the flagellar membrane of treated parasites. Bars $=500 \mathrm{~nm}$ (A, B, E) and $200 \mathrm{~nm}$ (C, D).

reported [21-28]. Mitochondria of trypanosomatids parasites exhibit unique structural and functional features that are remarkably distinct from mammalian counterparts. The absence of efficient mechanisms for ROS detoxification in these parasites make the mitochondrion a good target for drug intervention [29], and functional evaluation of the organelle by $\Delta \Psi \mathrm{m}$ measurement represents an important step for the examination of the mechanism of action of novel drugs [22-24,28]. Here, we assessed $\Delta \Psi \mathrm{m}$ by TMRE labeling in epimastigotes 


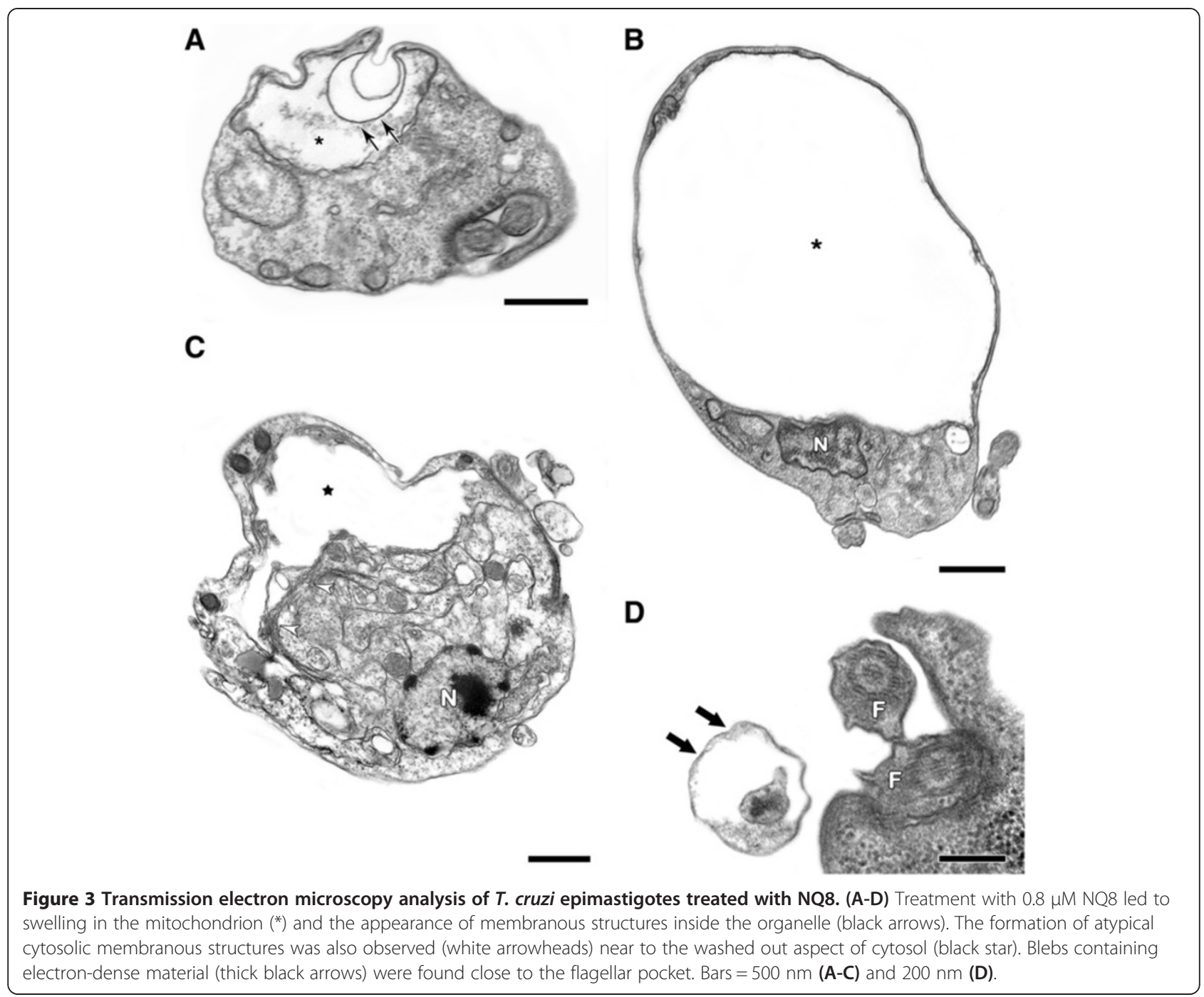

treated with NQs. We added FCCP as a control. This ionophore works as an uncoupling agent that impairs ATP synthesis by dissipating the hydrogen ion gradient and consequently stopping oxidative phosphorylation [30]. Flow cytometry revealed a decrease in the mitochondrial potential after incubation with the four NQs at their $\mathrm{IC}_{50}$ values, and in the case of NQ8, even at a concentration 4-fold lower (Table 4). Another parameter analyzed was the percentage of TMRE + parasites. We standardized the negative populations by the addition of $10 \mu \mathrm{M}$ FCCP, which totally dissipated the $\Delta \Psi \mathrm{m}$ in epimastigotes $( \pm 4 \% \mathrm{TMRE}+$ cells $)$. Interestingly, a reduction of about $20 \%$ in the TMRE + population was also observed in NQ8-treated parasites at the $\mathrm{IC}_{50}$. Such a decrease indicates that this naphthoquinone induces the appearance of a sub-population of parasites with metabolically inactive mitochondria.

Previous reports on the effects of several natural quinones, such as lapachol and $\beta$-lapachone, against $T$. cruzi have reported the involvement of free radicals in the trypanocidal activity [9,31], making the reduction of NQs by parasitic flavoenzymes a promising strategy for the development of trypanocidal drugs [32]. Mechanistically, it was reasonable to postulate that the collapse of the $\Delta \Psi \mathrm{m}$ was mediated by ROS generation in the treated parasites. In this context, the fluorescent probe DHE was used for intracellular ROS detection, and AA was added as a positive control because it inhibits the electron flow through the electron transport chain, leading to the accumulation of superoxide [33]. Among the four NQs tested, only NQ8 led to a discrete increase in the percentage of DHE + epimastigotes, giving addition evidence for the strong effect of this quinone on the parasite $\Delta \Psi \mathrm{m}$. Indeed, the pool of anti-oxidant defenses in epimastigotes that includes trypanothione, tryparedoxin peroxidase and other redox enzymes leads to a protective effect in this parasite stage, as previously described [34]. Thus, one plausible hypothesis to explain the absence of oxidative stress 

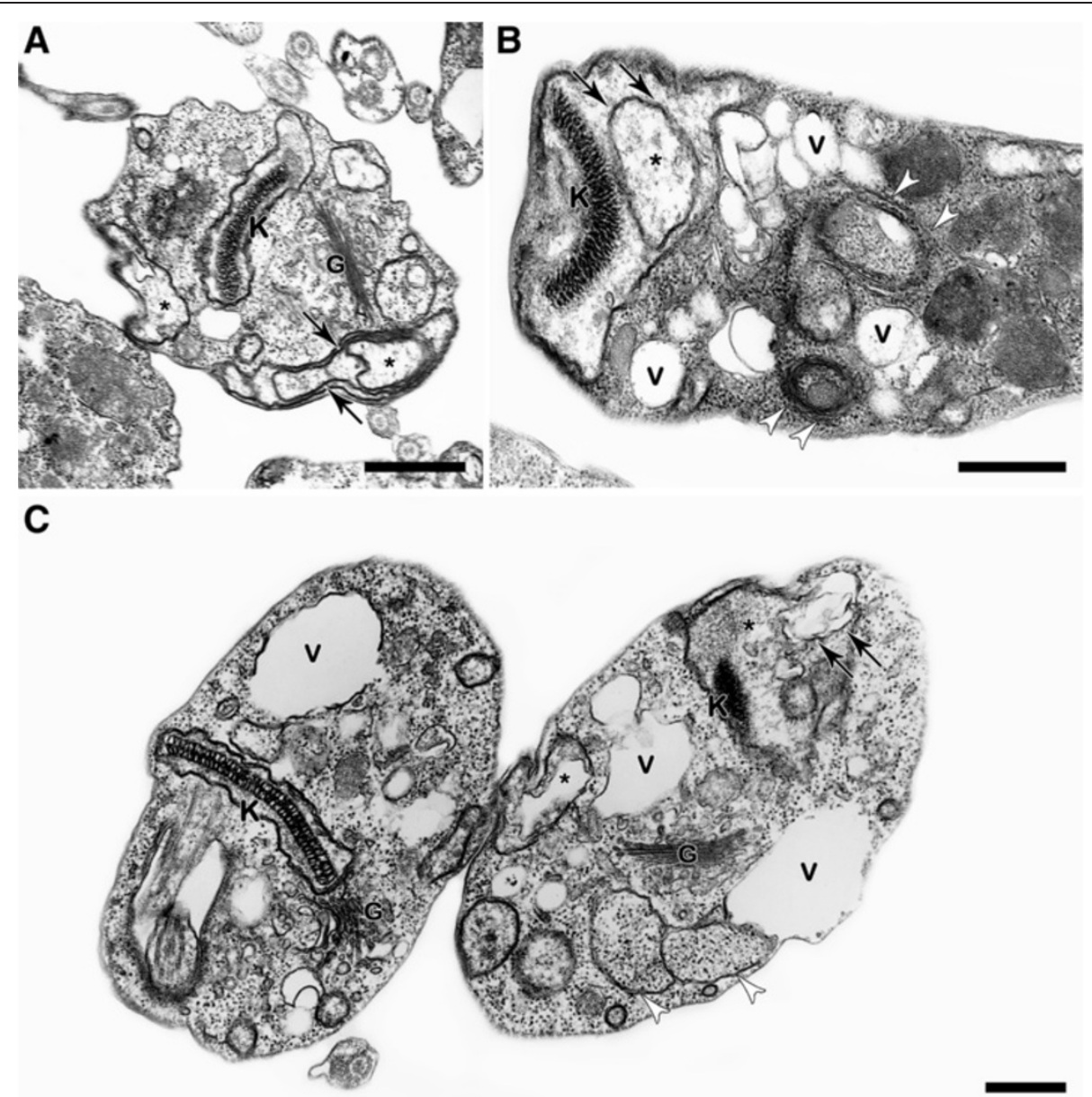

Figure 4 Transmission electron microscopy analysis of $T$. cruzi epimastigotes treated with NQ9. (A-C) This naphthoquinone (2.6 $\mu$ M) induced morphological alterations in the mitochondrion, including swelling $\left(^{*}\right)$ and the formation of membranous structures (black arrows) inside the organelle. Parasites treated with NQ9 also presented atypical cytosolic membranous structures (white arrowheads) and intense cytosolic vacuolization (V). Bars $=500 \mathrm{~nm}$.

triggered by NQ1, NQ9 and NQ12 could be the existence of more than one mechanism of action involved in the trypanocidal activity of these compounds, leaving ROS generation suppressed by the detoxification system of the parasite. Possibly, the strong redox effect of NQ8 could be associated to the presence of the acetyl group in its structure facilitating quinone reduction, as previously demonstrated by electrochemical analysis [35]. Further experiments using different biochemical and molecular approaches must be performed to better characterize ROS participation in the mechanism of action of these compounds.

Electron microscopy evidence of induction of the autophagic pathway by naphthoquinones and their derivatives has also been previously reported [24-26,28]. The presence of large profiles of endoplasmic reticulum surrounding different cellular structures, such as lipid droplets and organelles, and the appearance of bizarre membranous structures with a myelin-like aspect are the most common characteristics. The autophagic process represents a fundamental constitutive pathway in eukaryotic cells that is responsible for remodeling cellular structures and maintaining homeostasis. In trypanosomatids, other roles for autophagy have been proposed, including in the parasite's differentiation [36]. In a great variety of cell models, the loss of the balance between anabolic and catabolic processes leads to non-apoptotic death [37]. In the last decade, it has been demonstrated that the induction of autophagy in T. cruzi trypanosomatids is triggered by several classes of drugs, in particular naphthoquinones and their derivatives $[25,26,38]$. Our transmission electron microscopy analysis suggested the involvement of endoplasmic reticulum and cytosolic membranous structures in pre-autophagosomal formation, as previously postulated by Yotimitsu \& Klionsky [39].

Another ultrastructural alteration observed after the treatment with NQs was the development of blebs in the flagellar membrane, which was also previously reported 

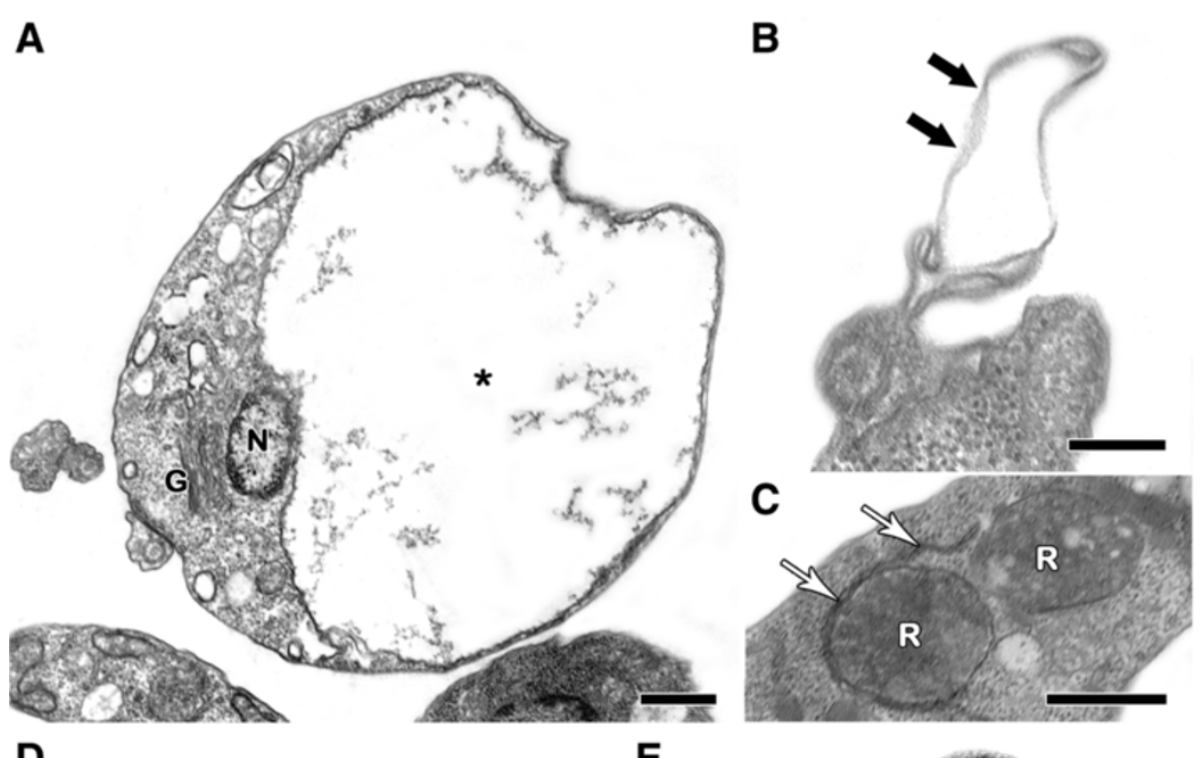

D

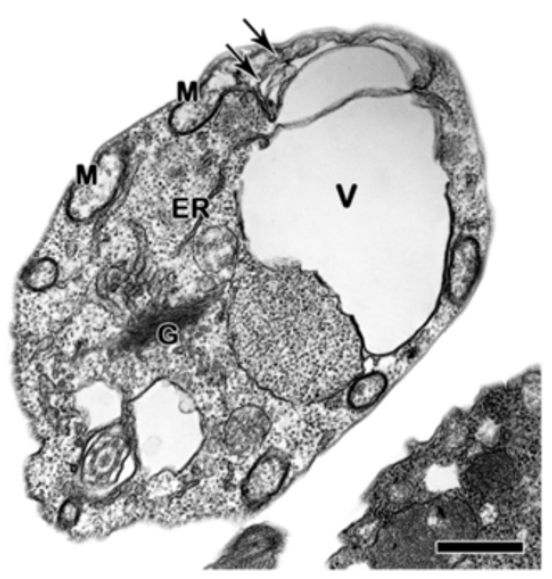

E

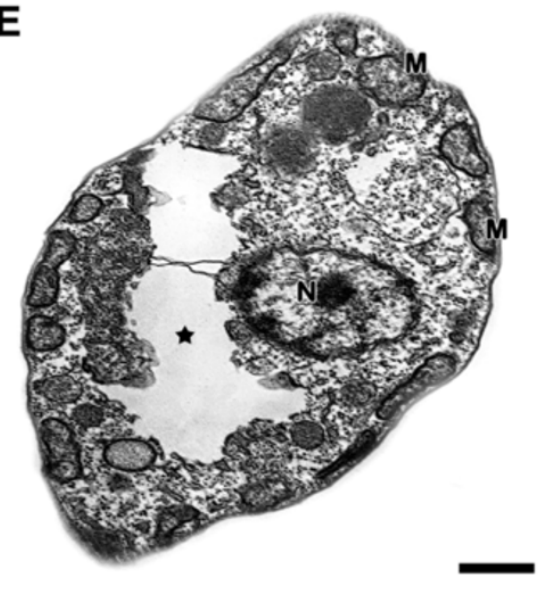

Figure 5 Transmission electron microscopy analysis of $T$. cruzi epimastigotes treated with NQ12. (A-E) Parasites treated with $0.5 \mu \mathrm{M}$ showed a strong mitochondrial swelling $\left(^{*}\right)$ with membranous structures in the organelle matrix (black arrows), the formation of flagellar blebs (thick black arrows) and the appearance of endoplasmic reticulum in close contact with the reservosome membranes (white arrows). An intense vacuolization $(\mathrm{V}$ ) and washed out aspect of the cytosol (black star) were also detected after treatment with NQ12. Bars = 500 nm (A, C-E) and $200 \mathrm{~nm}$ (B).

after treatment with naphthoquinone derivatives [23,25,26] and is commonly associated with apoptosis-like death in different cells [40].

\section{Conclusion}

Although the autophagic phenotype was the most frequently observed ultrastructural alteration in treated epimastigotes and bleb formation was the unique characteristic of an apoptosis-like process, a hypothesis that there is interplay between the distinct death pathways through a cross-talk signaling mechanism could not be discarded. Similar mechanisms have been demonstrated for other eukaryotic cells in the literature [41]. Especially in T. cruzi, the processes of death regulation are poorly understood and deserve further studies aimed at the development of new therapeutic agents.

\section{Methods}

\section{Compounds}

The naphthoquinone NQ1 (1,4-naphthoquinone) was purchased from Fluka (Sigma-Aldrich Chemical Co., St. Louis, USA), NQ2 (menadione) and NQ5 were purchased from Sigma-Aldrich, and NQ3 (lawsone) and NQ6 (dichlone) were purchased from Acros Organic (Geel, Belgium). Compound NQ4 was prepared by standard acetylation of NQ3 [14]. All the juglone derivatives (NQ7 to NQ15) were prepared according to methods described in the literature [14]. Juglone (NQ7) is a commercial material and, when needed on a large scale, was prepared according to the method by Tietze et al. [42] and purified by flash chromatography $[14,43,44]$. Acetylation of juglone under standard conditions yielded juglone acetate (5-acetoxy-1,4-naphthoquinone, NQ8) 
Table 4 Flow cytometry analysis of $\Delta \Psi_{m}$ and ROS production in $T$. cruzi epimastigotes

\begin{tabular}{|c|c|c|c|c|}
\hline \multirow[t]{2}{*}{ Cpd } & & \multicolumn{2}{|c|}{ TMRE } & \multirow{2}{*}{$\begin{array}{c}\text { DHE } \\
\% \text { cells+ }\end{array}$} \\
\hline & & $\%$ cells+ & $I^{a}$ & \\
\hline- & & $97.9 \pm 1.8^{b}$ & 0.00 & $3.9 \pm 1.8$ \\
\hline - & $+10 \mu \mathrm{M} \mathrm{FCCP}$ & $3.4 \pm 1.5$ & $-0.70^{*}$ & $-{ }^{c}$ \\
\hline- & $+22 \mu \mathrm{M}$ AA & - & - & $71.8 \pm 14.5$ \\
\hline \multirow[t]{3}{*}{ NQ1 } & $0.1 \mu \mathrm{M}$ & $98.6 \pm 1.7$ & 0.04 & $6.4 \pm 3.3$ \\
\hline & $0.2 \mu \mathrm{M}$ & $98.3 \pm 1.5$ & -0.07 & $4.7 \pm 2.2$ \\
\hline & $0.3 \mu \mathrm{M}$ & $96.1 \pm 4.1$ & $-0.22^{*}$ & $4.8 \pm 2.7$ \\
\hline \multirow[t]{3}{*}{ NQ8 } & $0.2 \mu \mathrm{M}$ & $97.4 \pm 3.1$ & $-0.18^{*}$ & $2.1 \pm 0.8$ \\
\hline & $0.4 \mu \mathrm{M}$ & $93.4 \pm 3.1$ & $-0.33^{*}$ & $2.9 \pm 1.5$ \\
\hline & $0.8 \mu \mathrm{M}$ & $76.7 \pm 14.4$ & $-0.53^{*}$ & $26.1^{*} \pm 9.9$ \\
\hline \multirow[t]{3}{*}{ NQ9 } & $0.6 \mu \mathrm{M}$ & $98.5 \pm 0.9$ & 0.09 & $5.9 \pm 2.0$ \\
\hline & $1.3 \mu \mathrm{M}$ & $96.0 \pm 5.1$ & 0.04 & $5.0 \pm 2.7$ \\
\hline & $2.6 \mu \mathrm{M}$ & $92.2 \pm 7.8$ & $-0.27^{*}$ & $7.5 \pm 4.7$ \\
\hline \multirow[t]{3}{*}{ NQ12 } & $0.1 \mu \mathrm{M}$ & $98.2 \pm 1.9$ & 0.08 & $6.3 \pm 2.7$ \\
\hline & $0.2 \mu \mathrm{M}$ & $97.1 \pm 3.8$ & 0.05 & $5.4 \pm 3.6$ \\
\hline & $0.5 \mu \mathrm{M}$ & $97.7 \pm 1.3$ & $-0.22^{*}$ & $7.2 \pm 3.8$ \\
\hline
\end{tabular}

${ }^{\mathrm{a}} \mathrm{IV}=(\mathrm{MT}-\mathrm{MC}) / \mathrm{MC}$, where MT corresponds to the marker median fluorescence for treated parasites, and $M C$ corresponds to that of control parasites. Negative IV values correspond to depolarization of the mitochondrial membrane.

${ }^{\mathrm{b}}$ Mean \pm standard deviation of 4 independent experiments. ${ }^{\mathrm{c}}$ Not determined.

Asterisks indicate significant differences in relation to the control group $\left({ }^{*} \mathrm{p} \leq 0.002\right)$.

[45]. The methoxy derivative NQ9 (5-methoxy-1,4naphthoquinone) was prepared by the methylation of NQ7 using methyl iodide and silver (I) oxide [42]. For the 2-bromojuglone derivatives, NQ10 was prepared according to Grunwell et al. [46] by oxidative bromination of 1,5-diacetoxynaphthalene. Starting with NQ10, we obtained NQ11 by standard acetylation and NQ12 by methoxylation [47]. The 3-bromojuglone derivatives were prepared by selective bromination of NQ7 according to Brimble \& Brenstrum [48], which yielded NQ13 as the major isomer. From this derivative, either by standard acetylation or methylation, NQ14 [47] and NQ15 [49], respectively, were obtained. NQ16, which combines the structural features of NQ2 and NQ7, was purchased from Sigma-Aldrich (Figure 1).

Stock solutions of the compounds were prepared in dimethylsulfoxide (DMSO), with the final concentration of the latter in the experiments never exceeding $0.1 \%$. Preliminary experiments showed that at concentrations of up to $0.5 \%$, DMSO has no deleterious effect on the parasites [50].

\section{Animals}

Albino Swiss mice were employed for the trypomastigotes and host cells obtention. This study is in accordance to the guidelines of the Colégio Brasileiro de Experimentação Animal (COBEA) and was performed in biosafety conditions. All the procedures in animal experimentation were approved by the Comissão de Ética em Experimentação Animal (CEUA/Fiocruz), license LW 16/13.

\section{Parasites}

All experiments were performed with the $\mathrm{Y}$ strain of $T$. cruzi. Epimastigote forms were maintained axenically at $28^{\circ} \mathrm{C}$ with weekly transfers in LIT medium and harvested during the exponential phase of growth. Bloodstream trypomastigotes were obtained from infected mice at the peak of parasitemia by differential centrifugation.

\section{Effect on bloodstream trypomastigotes}

The parasites were resuspended to a concentration of $10 \times 10^{6}$ cells $/ \mathrm{mL}$ in DMES medium. This suspension $(100 \mu \mathrm{L})$ was added to the same volume of each of the sixteen naphthoquinones (NQs), which had been previously prepared at twice the desired final concentrations. The incubation was performed in 96-well microplates (Nunc Inc., Rochester, USA) at $4^{\circ} \mathrm{C}$ or $37^{\circ} \mathrm{C}$ for $24 \mathrm{~h}$ at concentrations in the range of 0.06 to $1000 \mu \mathrm{M}$. Benznidazole (Laboratório Farmacêutico do Estado de Pernambuco, Brazil) the standard drug for treatment of chagasic patients was used as control. For experiments performed in the presence of $100 \%$ blood, the parasites were resuspended in mouse blood to a concentration of $5 \times 10^{6} \mathrm{cells} / \mathrm{mL}$, and $196 \mu \mathrm{L}$ of the suspension was added to each well together with $4 \mu \mathrm{L}$ of the NQs (0.06 to $1000 \mu \mathrm{M})$, which had been selected on the basis of the results of previous experiment and had been prepared at a concentration 50 times higher than the final concentration desired. Cell counts were performed in a Neubauer chamber, and the activity of the compounds corresponding to the concentration that led to $50 \%$ lysis of the parasites was expressed as the $\mathrm{IC}_{50} / 1$ day.

\section{Effect on epimastigotes}

The parasites were resuspended in LIT medium to a parasite concentration of $10 \times 10^{6}$ cells $/ \mathrm{mL}$. This suspension was added to the same volume of the NQs (NQ1, NQ8, NQ9 and NQ12) at concentrations in the range of 0.06 to $10 \mu \mathrm{M}$ and then incubated at $28^{\circ} \mathrm{C}$ in 24-well plates (Nunc Inc.). Cell counts were performed daily (from 1 to 4 days) in a Neubauer chamber, and the activity of the compounds was expressed as $\mathrm{IC}_{50}$, which corresponds to the concentration that leads to $50 \%$ proliferation inhibition.

\section{Effect on intracellular amastigotes}

Peritoneal macrophages were obtained from mice and plated in 24-well plates $\left(3 \times 10^{5}\right.$ cells/well) (Nunc Inc., 
IL, USA) for $24 \mathrm{~h}$. Then, the cultures were infected with trypomastigotes (10:1 parasite:host cell) in DMES medium. After $3 \mathrm{~h}$ of incubation, the cultures were washed to remove non-internalized parasites, and the selected NQs were added at final concentrations ranging from 0.5 to $20 \mu \mathrm{M}$. Alternatively, primary cultures of mouse embryo heart muscle cells (HMCs) [51] were used. Briefly, the hearts of 18-day-old mouse embryos were fragmented and dissociated with trypsin and collagenase in phosphate buffered saline (PBS), pH 7.2. Thereafter, the cells were resuspended in Dulbecco's modified Eagle's medium supplemented with horse and fetal calf sera, chicken embryo extract, $\mathrm{CaCl}_{2}$ and L-glutamine; then, the cells were plated onto gelatin-coated glass coverslips $\left(10^{5}\right.$ cells/well $)$ and maintained at $37^{\circ} \mathrm{C}$ in $5 \% \mathrm{CO}_{2}$ atmosphere. The HMCs were plated onto gelatine-coated glass coverslips in 24-well plates $\left(10^{5}\right.$ cells/well $)$ and infected at a 10:1 parasite:host cell ratio after $24 \mathrm{~h}$. Afterwards the cultures were washed, and the NQs (0.5 to $20 \mu \mathrm{M})$ were added. At specified intervals, the cultures were fixed in Bouin's solution, stained with Giemsa and counted to assess the following parameters: percentage of cells infected, number of parasites/infected cell and the endocytic index (EI), which refers to the number of parasites/100 cells [52]. The $\mathrm{IC}_{50}$ values for the different days of treatment, corresponding to the concentration that led to $50 \%$ inhibition of each parameter, were calculated. To determine the possible toxic effects of the compounds on the host cells, uninfected macrophages and HMCs were incubated at $37^{\circ} \mathrm{C}$ with the NQs. After 2 days, the viability of the cells was measured using the MTT colorimetric assay [53]. The absorbance was measured at $490 \mathrm{~nm}$ with a spectrophotometer (VERSAmax Tunable, Molecular Devices, USA), allowing for the determination of an $\mathrm{LC}_{50}$ value, which is the concentration that reduces cellular viability by $50 \%$.

\section{Transmission and scanning electron microscopy analysis} Epimastigotes $\left(5 \times 10^{6}\right.$ cells $\left./ \mathrm{mL}\right)$ were treated for $24 \mathrm{~h}$ with the selected $\mathrm{NQs}$ at their respective $\mathrm{IC}_{50} / 24 \mathrm{~h}$ values in LIT medium at $28^{\circ} \mathrm{C}$. Afterward, they were fixed with $2.5 \%$ glutaraldehyde in $0.1 \mathrm{M} \mathrm{Na}$-cacodylate buffer ( $\mathrm{pH} 7.2$ ) for $40 \mathrm{~min}$ at $25^{\circ} \mathrm{C}$ and post-fixed with $1 \% \mathrm{OsO}_{4}, 0.8 \%$ potassium ferricyanide and $2.5 \mathrm{mM}$ $\mathrm{CaCl}_{2}$ in the same buffer for $20 \mathrm{~min}$ at $25^{\circ} \mathrm{C}$. The cells were dehydrated in an ascending acetone series and embedded in PolyBed 812 resin. Ultrathin sections were stained with uranyl acetate and lead citrate and examined in a Jeol JEM1011 transmission electron microscope (Tokyo, Japan). Alternatively, dehydrated samples were dried by the critical point method with $\mathrm{CO}_{2}$, mounted on aluminum stubs, coated with a $20 \mathrm{~nm}$ thick gold layer and examined on a Jeol JSM6390LV scanning electron microscope (Tokyo, Japan). Both electron microscopes are located in Plataforma de Microscopia Eletrônica at Instituto Oswaldo Cruz (Fiocruz).

\section{Flow cytometry analysis}

Epimastigotes were treated for $24 \mathrm{~h}$ with the NQs at concentrations up to their $\mathrm{IC}_{50}$ values. We then determined the mitochondrial membrane potential $(\Delta \Psi \mathrm{m})$ and reactive oxygen species (ROS) production. For $\Delta \Psi \mathrm{m}$ analysis, the parasites were incubated with $50 \mathrm{nM}$ tetramethylrhodamine (TMRE) (Molecular Probes, Carlsbad, USA) for $15 \mathrm{~min}$ at $28^{\circ} \mathrm{C}$, using $10 \mu \mathrm{M}$ carbonyl cyanide 4(trifluoromethoxy)phenylhydrazone (FCCP) (Sigma-Aldrich Chemical Co.) as a control for $\Delta \Psi \mathrm{m}$ dissipation. Alterations in TMRE fluorescence were quantified using an index of variation (IV), which was calculated using the equation (MT - MC)/MC, where MT is the median of fluorescence for treated parasites and $\mathrm{MC}$ is the median of fluorescence of the control parasites. Negative IV values correspond to depolarization of the mitochondrial membrane [54]. To evaluate ROS generation, labeling with $10 \mu \mathrm{M}$ dihydroethidium (DHE) (Molecular Probes) for $30 \mathrm{~min}$ at $28^{\circ} \mathrm{C}$ was performed, using $22 \mu \mathrm{M}$ antimycin $\mathrm{A}$ (AA) (Sigma-Aldrich) as the positive control. The samples were analyzed in a FACSCalibur flow cytometer (Becton Dickinson, CA, USA) equipped with the Cell Quest software (Joseph Trotter, Scripps Research Institute, La Jolla, USA). A total of 10,000 events were acquired in the region previously established as that of the parasites.

\section{Statistical analysis}

The comparison between control and treated groups was performed using the Mann-Whitney test. Differences with $p \leq 0.05$ were considered statistically significant.

\section{Competing interests}

The authors declare that they have no competing interests.

\section{Authors' contributions}

KS and NAS performed the trypanocidal activity assays. MTM synthesized the naphthoquinone derivatives. RFSMB and NAS designed and performed the electron microscopy and flow cytometry assays. SLC contributed to the design and supervision of the experiments. SLC and RFSMB wrote the manuscript. All authors have read and approved the final manuscript.

\section{Acknowledgments}

Funding was provided by Fundação de Amparo à Pesquisa do Rio de Janeiro (FAPERJ), Conselho Nacional de Desenvolvimento Científico e Tecnológico (CNPq), Fundação Oswaldo Cruz (FIOCRUZ) and Spanish MICINN (Project SAF 2009-10399, to MTM).

\section{Author details}

'Laboratório de Biologia Celular, Instituto Oswaldo Cruz, Fundação Oswaldo Cruz, Av. Brasil 4365, Manguinhos, Rio de Janeiro RJ 21040-900, Brazil.

${ }^{2}$ Instituto de Química Médica, CSIC, Juan de la Cierva 3, Madrid 28006, Spain.

Received: 9 May 2013 Accepted: 30 August 2013

Published: 3 September 2013

\section{References}

1. Rocha MO, Teixeira MM, Ribeiro AL: An update on the management of Chagas' cardiomyopathy. Exp Rev Anti-Infective Ther 2007, 5:727-743. 
2. Rassi A Jr, Rassi A, Marin-Neto JA: Chagas' disease. Lancet 2010, 375:1388-1402. 3. Schmunis GA, Yadon ZE: Chagas disease: a Latin American health problem becoming a world health problem. Acta Trop 2010, 115:14-21.

4. Soeiro MNC, De Castro SL: Screening of potential anti-Trypanosoma cruzi candidates: In vitro and in vivo studies. Open Med Chem J 2011, 5:21-30.

5. O'Brien PJ: Molecular mechanisms of quinone cytotoxicity. Chem Biol Interact 1991, 80:1-41.

6. Bastien JW: Pharmacopeia of qollahuaya Andeans. J Ethnopharmacol 1983, 8:97-111.

7. Arenas P: Medicine and magic among the maka Indians of the Paraguayan Chaco. J Ethnopharmacol 1987, 21:279-295.

8. Constantino L, Barlocco D: Privileged structures as leads in medicinal chemistry. Curr Med Chem 2006, 13:65-85.

9. Pinto AV, De Castro SL: The trypanocidal activity of naphthoquinones: a review. Molecules 2009, 14:4570-4590.

10. Salas CO, Faúndez M, Morello A, Maya JD, Tapia RA: Natural and synthetic naphthoquinones active against Trypanosoma cruzi: an initial step towards new drugs for Chagas' disease. Curr Med Chem 2011, 18:144-161.

11. Bolton $J$, Trush MA, Penning TM, Dryhurst G, Monks TJ: Role of quinones in toxicology. Chem Res Toxicol 2000, 13:135-160.

12. Babula P, Adam V, Kizek R, Sladky Z, Havel L: Naphthoquinones as allelochemical triggers of programmed cell death. Environm Exp Bot 2009, 65:330-337.

13. Esnault S, Braun RK, Shen ZJ, Xiang Z, Heninger E, Love RB, Sandor M, Malter JS: Pin1 modulates the type 1 immune response. PLoS One 2007, 2:e226.

14. Montenegro RC, Molina MT, Araújo AJ, Marinho Filho JDB, Rocha DD, Lopéz-Montero E, Goulart MO, Bento ES, Alves APNN, Pessoa C, Moraes MO, Costa-Lotufo LV: Cytotoxic activity of naphthoquinones with special emphasis on juglone and its 5-O-methyl derivative. Chem Biol Interact 2010, 184:439-448

15. Xu HL, Yu XF, Qu SC, Zhang R, Qu XR, Chen YP, Ma XY, Sui DY: Antiproliferative effect of juglone from juglans mandshurica maxim on human leukemia cell $\mathrm{HL}-60$ by inducing apoptosis through the mitochondria-dependent pathway. Eur J Pharmacol 2010, 645:4-22.

16. Ribeiro KAL, Carvalho CM, Molina MT, Lima EP, López-Montero E, Reys JRM, Oliveira MBF, Pinto AV, Santana AEG, Goulart MOF: Activities of naphthoquinones against Aedes aegypti, vector of dengue and Biomphalaria glabrata, intermediate host of Schistosoma mansoni. Acta Trop 2009, 111:44-50.

17. Pinto AV, Neves Pinto C, Pinto MCFR, Santa-Rita RM, Pezzella C, De Castro SL: Trypanocidal activity of synthetic heterocyclic derivatives from active quinones from Tabebuia sp. Arzneim-Forsch 1997, 47(I):74-79.

18. Fournet A, Angelo A, Muñoz V, Roblot F, Hocquemiller R, Cavé A: Biological and chemical studies of Pera benensis, a Bolivian plant used in folk medicine as a treatment of cutaneous leishmaniasis. J Ethnopharmacol 1992, 37:159-164.

19. Fournet A, Barrios AA, Muñoz V: Leishmanicidal and trypanocidal activities of Bolivian medicinal plants. J Ethnopharmacol 1994, 41:19-37.

20. Lopes JN, Cruz FS, Docampo R, Vasconcellos ME, Sampaio MC, Pinto AV, Gilbert B: In vitro and in vivo evaluation of the toxicity of 1,4naphthoquinone and 1,2-naphthoquinone derivatives against Trypanosoma cruzi. Ann Trop Med Parasitol 1978, 72:523-531.

21. Docampo R, De Souza W, Cruz FS, Roitman I, Cover B, Gutteridge WE: Ultrastructural alterations and peroxide formation induced by naphthoquinones in different stages of Trypanosoma cruzi. Z Parasitenkd 1978, 57:189-198.

22. Menna-Barreto RFS, Henriques-Pons A, Pinto AV, Morgado-Diaz JA, Soares MJ, De Castro SL: Effect of a $\beta$-lapachone-derived naphthoimidazole on Trypanosoma cruzi: identification of target organelles. J Antimicrob Chemother 2005, 56:1034-1041.

23. Menna-Barreto RFS, Corrêa JR, Pinto AV, Soares MJ, De Castro SL: Mitochondrial disruption and DNA fragmentation in Trypanosoma cruzi induced by naphthoimidazoles synthesized from $\beta$-lapachone. Parasitol Res 2007, 101:895-905.

24. Menna-Barreto RFS, Goncalves RL, Costa EM, Silva RS, Pinto AV, Oliveira MF, De Castro SL: The effects on Trypanosoma cruzi of novel synthetic naphthoquinones are mediated by mitochondrial dysfunction. Free Radic Biol Med 2009, 47:644-653.

25. Menna-Barreto RFS, Salomão K, Dantas AP, Santa-Rita RM, Soares MJ, Barbosa HS, De Castro SL: Different cell death pathways induced by drugs in Trypanosoma cruzi: an ultrastructural study. Micron 2009, 40:157-168.
26. Menna-Barreto RFS, Corrêa JR, Cascabulho CM, Fernandes MC, Pinto AV, Soares MJ, De Castro SL: Naphthoimidazoles promote different death phenotypes in Trypanosoma cruzi. Parasitology 2009, 136:499-510.

27. Menna-Barreto RFS, Beghini DG, Ferreira AT, Pinto AV, De Castro SL, Perales $\mathrm{J}$ : A proteomic analysis of the mechanism of action of naphthoimidazoles in Trypanosoma cruzi epimastigotes in vitro. J Proteomics 2010, 73:2306-2315.

28. Fernandes MC, Silva EN Jr, Pinto AV, De Castro SL, Menna-Barreto RFS: A novel triazolic naphthofuranquinone induces autophagy in reservosomes and impairment of mitosis in Trypanosoma cruzi. Parasitology 2012, 139:26-36

29. Soeiro MNC, De Castro SL: Trypanosoma cruzi targets for new chemotherapeutic approaches. Exp Opin Ther Targets 2009, 13:105-121.

30. Terada $H$ : The interaction of highly active uncouplers with mitochondria. Biochem Biophys Acta 1981, 639:225-242.

31. Docampo R, Cruz FS, Boveris A, Muniz RP, Esquivel DM: Lipid peroxidation and the generation of free radicals, superoxide anion, and hydrogen peroxide in $\beta$-lapachone-treated Trypanosoma cruzi epimastigotes. Arch Biochem Biophys 1978, 186:292-297.

32. Salmon-Chemin L, Buisine E, Yardley V, Kohler S, Debreu MA, Landry V Sergheraert C, Croft SL, Krauth-Siegel RL, Davioud-Charvet E: 2- and 3Substituted 1,4-naphthoquinone derivatives as subversive substrates of trypanothione reductase and lipoamide dehydrogenase from Trypanosoma cruzi: synthesis and correlation between redox cycling activities and in vitro cytotoxicity. J Med Chem 2001, 44:548-565.

33. Dumont A, Hehner SP, Hofmann TG, Ueffing M, Dröge W, Schmitz ML: Hydrogen peroxide-induced apoptosis is CD95-independent, requires the release of mitochondria-derived reactive oxygen species and the activation of NF-KB. Oncogene 1999, 18:747-757.

34. Irigoin F, Cibils L, Comini MA, Wilkinson SR, Flohe L, Radi R: Insights into the redox biology of Trypanosoma cruzi: Trypanothione metabolism and oxidant detoxification. Free Rad Biol Med 2008, 45:733-742.

35. Costa EO, Molina MT, Abreu FC, Silva FAS, Costa CO, Pinho W Jr, Valentim IB, Aguilera-Venegas B, Pérez-Cruz F, Norambuena E, Olea-Azar C, Goulart MOF: Electrochemical and spectroscopic investigation of bioactive naphthoquinones. Int J Electrochem Sci 2012, 7:6524-6538.

36. Duszenko M, Ginger ML, Brennand A, Gualdrón-López M, Colombo MI, Coombs GH, Coppens I, Jayabalasingham B, Langsley G, De Castro SL, Menna-Barreto RFS, Mottram JC, Navarro M, Rigden DJ, Romano PS, Stoka V, Turk B, Michels PA: Autophagy in protists. Autophagy 2011, 7:127-158.

37. Baehrecke EH: Autophagy: dual roles in life and death? Nat Rev in Mol Cell Biol 2005, 6:505-510.

38. Bera A, Singh S, Nagaraj R, Vaidya T: Induction of autophagic cell death in Leishmania donovani by antimicrobial peptides. Mol Biochem Parasitol 2003, 127:23-35.

39. Yorimitsu T, Klionsky DJ: Eating the endoplasmic reticulum: quality control by autophagy. Trends Cell Biol 2007, 17:279-285.

40. Walker NI, Harmon BV, Gobé GC, Kerr JF: Patterns of cell death methods. Arch Exp Pathol 1988, 13:18-54

41. Guimarães CA, Linden R: Programmed cell death: apoptosis and alternative death styles. Eur J Biochem 2004, 271:1638-1650.

42. Tietze LF, Güntner C, Gericke KM: A Diels-Alder reaction for the total synthesis of the novel antibiotic antitumor agent mensacarcin. Eur J Org Chem 2005, 12:2459-2467.

43. Molina MT, Navarro C, Moreno A, Csákÿ AG: Arylation of benzo-fused 1,4quinones by the addition of boronic acids under dicationic $\mathrm{Pd}(\mathrm{II})$ catalysis. Org Lett 2009, 11:4938-4941.

44. Ortega A, Rincón Á, Jiménez-Aliaga KL, Bermejo-Bescós P, Martín-Aragón S, Molina MT, Csákÿ AG: Synthesis and evaluation of arylquinones as BACE1 inhibitors, $\beta$-amyloid peptide aggregation inhibitors, and destabilizers of preformed $\beta$-amyloid fibrils. Bioorg Med Chem Lett 2011, 21:2183-2187.

45. Fieser LF, Dunn JT: Addition of dienes to halogenated and hydroxylated naphthoquinones. J Am Chem Soc 1937, 59:1016-1021.

46. Grunwell JR, Karipides A, Wigal CT, Heinzman SW, Parlow J, Surso JA Clayton L, Fleitz FJ, Daffner M, Stevens JE: The formal oxidative addition of electon-rich transoid dienes to bromonaphthoquinones. J Org Chem 1991, 56:91-95.

47. Parker KA, Sworin ME: Assignment of regiochemistry to substituted naphthoquinones by bromo juglone derivatives chemical and spectroscopic methods amino-, hydroxy-, and bromojuglone derivatives. J Org Chem 1981, 46:3218-3223. 
48. Brimble MA, Brenstrum TJ: C-Glycosylation of tri-O-benzyl-2-deoxy-Dglucose: synthesis of naphthyl substituted 3,6-dioxabicyclo [322] nonanes. J Chem Soc Perkin 2001, 1:1612-1623.

49. Tietze LF, Gericke KM, Schuberth I: Synthesis of highly functionalized anthraquinones and evaluation of their antitumor activity. Eur J Org Chem 2007, 27:4563-4577.

50. De Castro SL, Pinto MCFR, Pinto AV: Screening of natural and synthetic drugs against Trypanosoma cruzi: I-Establishing a structure/activity relationship. Microbios 1994, 78:83-90.

51. Meirelles MNL, Araujo-Jorge TC, Miranda CF, De Souza W, Barbosa HS: Interaction of Trypanosoma cruzi with heart muscle cells: ultrastructural and cytochemical analysis of endocytic vacuole formation and effect upon myogenesis in vitro. Eur J Cell Biol 1986, 41:198-206.

52. Salomão K, De Souza EM, Carvalho AS, Silva EF, Fraga CAM, Barbosa HS, De Castro SL: In vitro and in vivo activity of 1,3,4-thiadiazole-2-arylhydrazone derivatives of megazol on Trypanosoma cruzi. Antimicrob Agents Chemother 2010, 54:2023-2031.

53. Mosmann T: Rapid colorimetric assay for cellular growth and survival: application to proliferation and cytotoxicity assays. J Immunol Meth 1983, 65:55-63.

54. Santa-Rita RM, Henriques-Pons A, Barbosa HS, De Castro SL: Effect of the lysophospholipid analogues edelfosine, ilmofosine and miltefosine against Leishmania amazonensis. J Antimicrob Chemother 2004, 54:704-710.

doi:10.1186/1471-2180-13-196

Cite this article as: Salomão et al:: Trypanosoma cruzi mitochondrial swelling and membrane potential collapse as primary evidence of the mode of action of naphthoquinone analogues. BMC Microbiology 2013 13:196.

\section{Submit your next manuscript to BioMed Central and take full advantage of:}

- Convenient online submission

- Thorough peer review

- No space constraints or color figure charges

- Immediate publication on acceptance

- Inclusion in PubMed, CAS, Scopus and Google Scholar

- Research which is freely available for redistribution 